Título da Exposição: Vila Dique: Entre o transitório e o permanente

Autor(es) : Débora Wobeto

Agência(s)

Financiadora(s) da exposição: Navisual/ PPGAS/IFCH/UFRGS

Pesquisa e Instituição: “Antropologia Visual do Núcleo de Antropologia Visual” (iniciação científica) PPGAS-UFRGS

Cidade e data de Pesquisa: Porto Alegre, RS, 2014.

Orientação: Profa. Dra. Cornelia Eckert - PPGAS - UFRGS

Local de Exposição: Galeria Olho Nu, IFCH, UFRGS, Porto Alegre, RS.

Período de Exposição: 06 de Maio à 16 de Junho de 2014

Curadoria/Equipe de Montagem: Rumi Kubo, Fabrício Barreto, Juliana Goulart, Aline Renner, Aline Rochedo, Roberta Simon, Fabiela Bigossi, Cornelia Eckert, Gabriela Jacobsen, José Luís Abalos Júnior

Ficha Técnica: 2 fotos de $18 \mathrm{~cm}$ x $25 \mathrm{~cm}$

1 foto de $20 \mathrm{~cm} \times 30 \mathrm{~cm}$

5 fotos de $35 \mathrm{~cm} \times 53 \mathrm{~cm}$

4 fotos de $25 \mathrm{~cm} \times 35 \mathrm{~cm}$

Instalações: Monóculos pendurados sobre mapas desenhados;

Cabide de memórias com fotos do território da

Vila Dique Porto Novo + peça de roupa;

Caixas de mudança com artefatos do dia a dia

Câmera e lente(s) utilizada(s): Sony Cyber Shot DSC W630 ;

Canon PowerShot G12;

Nikon D3100

Fotos da resenha GOULART, Juliana, BARRETO, Fabrício. Maio de 2014. Galeria Olho Nu, IFCH, UFRGS, Porto Alegre, RS.

Forma de citação da resenha: GOULART, Juliana. Vila Dique: Entre o transitório e o permanente. Revista Iluminuras [on line], Porto Alegre, V.15, nº 35

\title{
VILA DIQUE: ENTRE O TRANSITÓRIO E O PERMANENTE
}

\section{Juliana Goulart ${ }^{1}$}

“A vida das pessoas cabe nesse quadrado?” Talvez essa seja a questão norteadora do trabalho de Débora Wobeto, graduanda em Ciências Sociais - UFRGS, que há dois anos acompanha a remoção dos moradores da Vila Dique.

${ }^{1}$ Universidade Federal do Rio Grande do Sul, Brasil.

Iluminuras, Porto Alegre, v. 15, n. 35, p. 451-461, jan./jul. 2014 
A Vila Dique configura como uma área de ocupação próxima ao Aeroporto Internacional Salgado Filho, em Porto Alegre (RS) e desde 2009 os moradores estão em processo de remoção para o Conjunto Habitacional Porto Novo, na zona sul da capital.

A partir do Projeto Memórias da Vila Dique - parceria entre a faculdade de Educação/UFRGS e o Grupo Hospital Conceição -, a pesquisa de Débora implicou em sua inserção na vida cotidiana desta população, em especial tratou do drama da remoção dos moradores da Vila que encontravam-se entre a desconfiguração das suas histórias e a construção de um novo modelo de interação social.

Esse estado de imprevisibilidade acompanhou a Vila Dique por muito tempo. Embora há 20 anos lutassem por uma remoção, somente com a confirmação da Copa do mundo de futebol de 2014, é que o Estado se interessou por essa mudança e passou a efetivá-la. Ainda que tarde, um desejo atendido. Todavia, a transitoriedade da remoção, frustrou os moradores pela forma como foi feita. Ora obtinham informações, ora não e entre a espera e a surpresa, o Departamento Municipal de Habitação, que foi premiado como Remoção Exemplar, concretizava as mudanças, pouco a pouco.

Daí a provocação da autora sobre pessoas vivendo em um quadrado. Antes dizem viviam em casas com pátios ${ }^{1}$, tinham certa privacidade e práticas de boa vizinhança, hoje habitam um espaço de $36 \mathrm{~m}^{2}$, sem espaço de lazer e remodela o novo contexto de morar com sociabilidades cotidianas.

A exposição Vila Dique: entre o transitório e permanente abre, com a visualização dessas diferenças, talvez a mais drástica de todo esse movimento: o espaço físico. A interação que este módulo a seguir propõe, é justamente a metáfora do quadrado, de uma nova realidade, onde as pessoas encaixaram suas vidas.

\footnotetext{
${ }^{1}$ RS e algumas regiões de Santa Catarina e Paraná: quintal.
} 


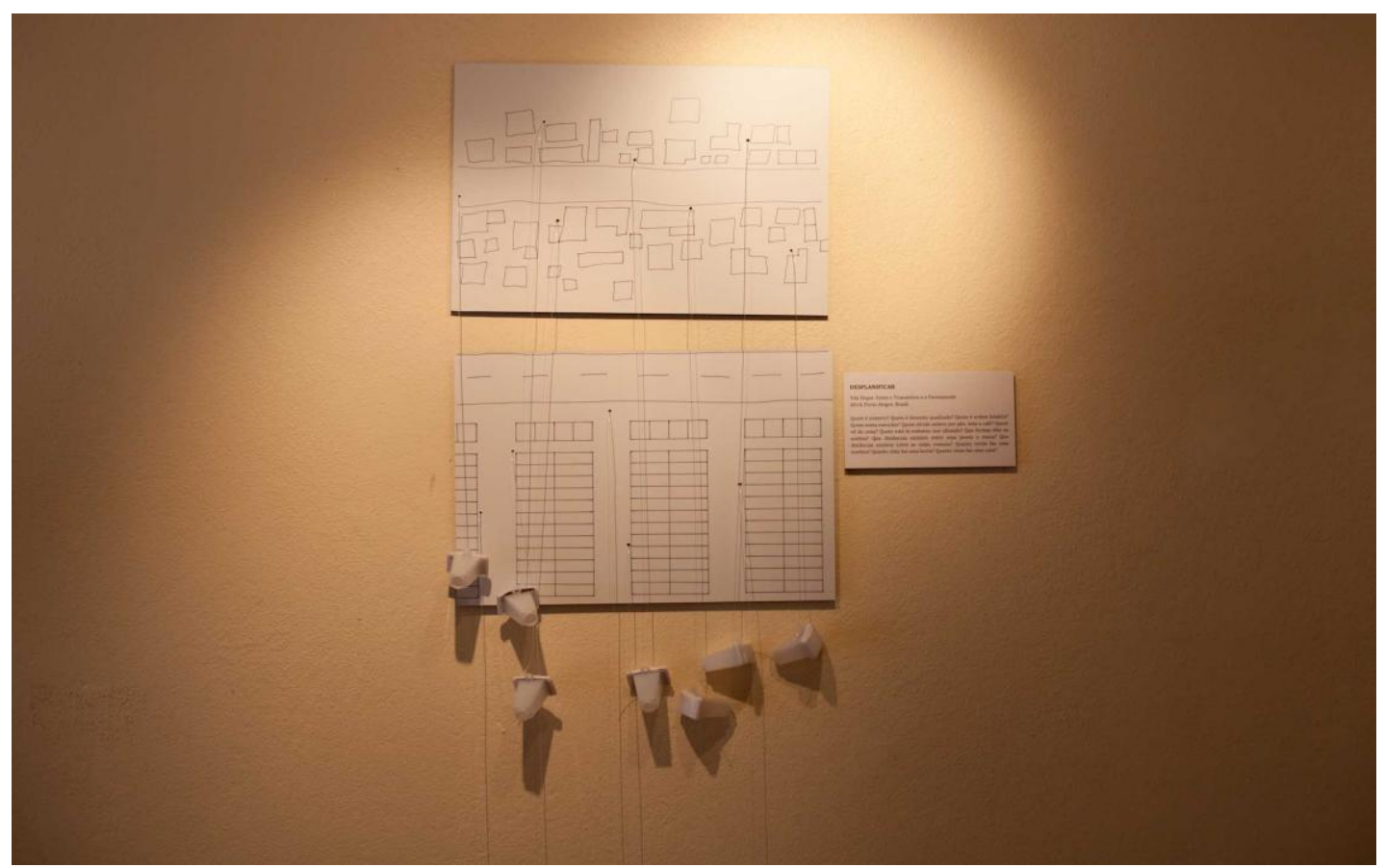

Foto 1 - Monóculos com fotos das casas na vila (acima) e no Conjunto Habitacional (abaixo). Foto: Juliana Goulart

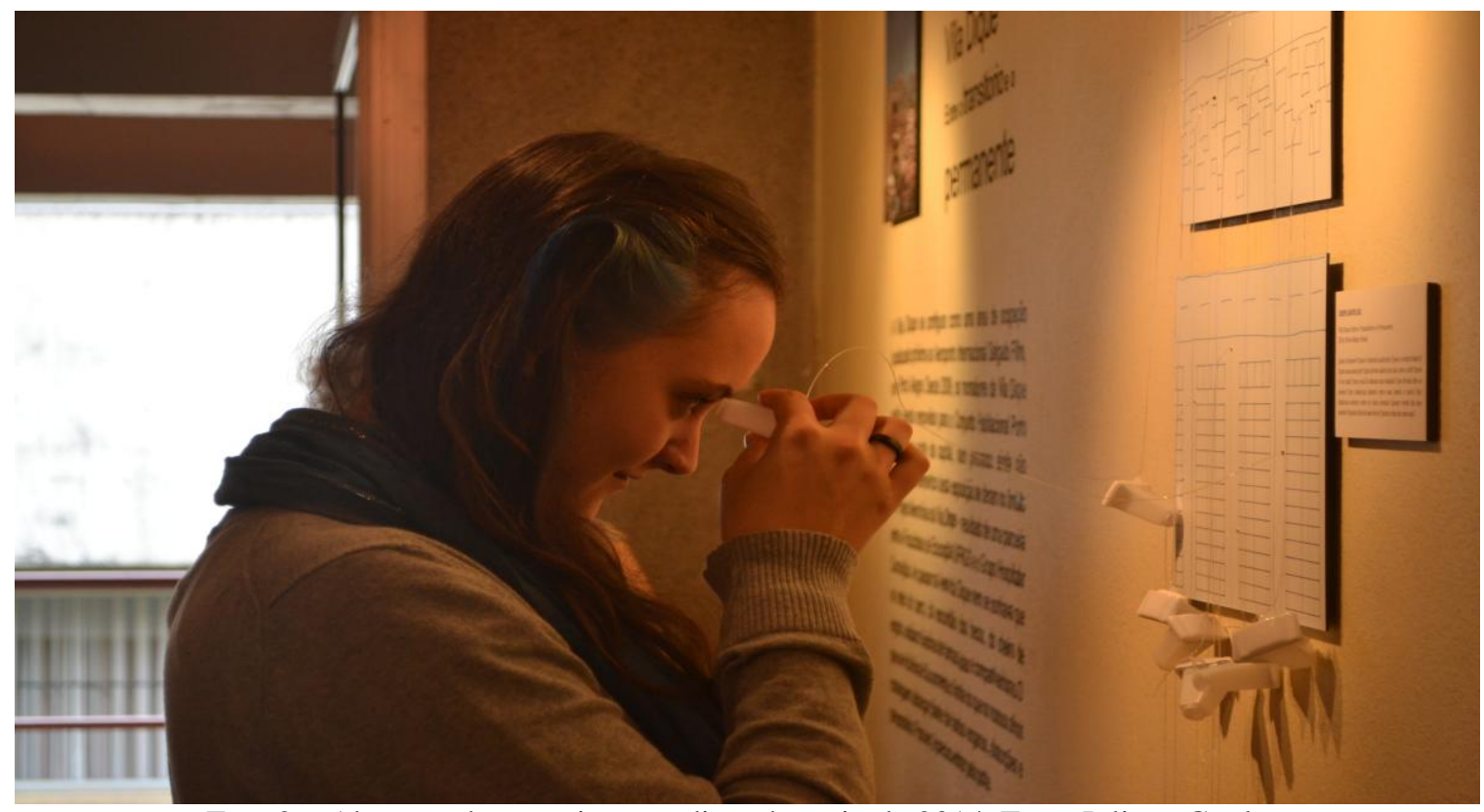

Foto 2 - Abertura da exposição no dia 6 de maio de 2014. Foto: Juliana Goulart

Na sequência a exposição mostra a vila sendo demolida, em um momento de desconfiguração, como a própria pesquisadora-fotógrafa denomina, mas ainda carregada

Iluminuras, Porto Alegre, v. 15, n. 35, p. 451-461, jan./jul. 2014 
de traços das pessoas que passaram por lá, como uma matéria que testemunha trajetórias sociais.

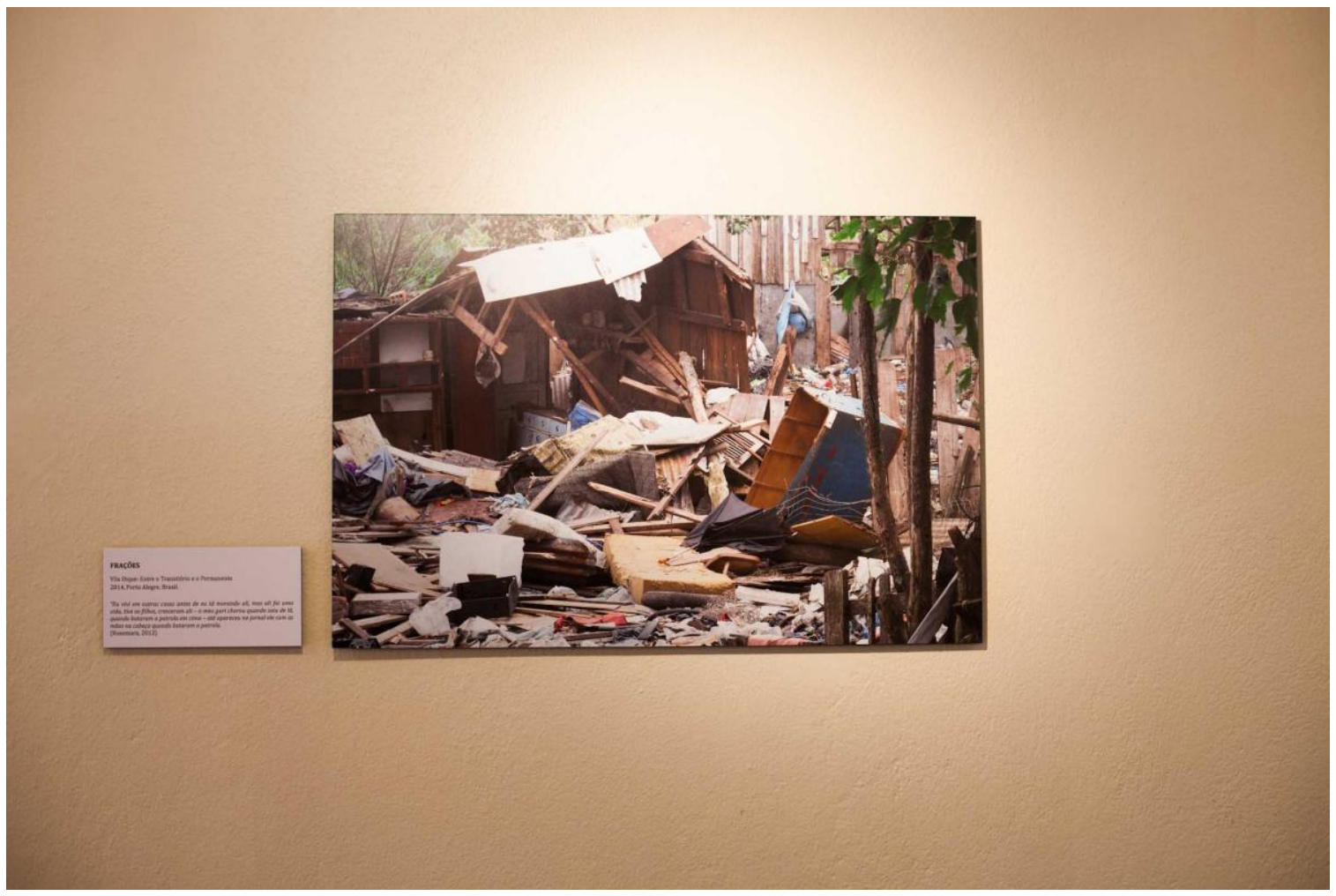

Foto 3 - Foto da destruição da Vila Dique durante a remoção.

Débora iniciou-se no método etnográfico através da disciplina Antropologia Visual, ministrada pela Profa. Dra. Cornelia Eckert, no curso de Ciências Sociais, UFRGS em 2013/02. Trata-se de uma disciplina em que e equipe do Núcleo de Antropologia Visual participa de todas as etapas de ensino e aprendizado, colaborando no processo de formação dos discentes. No final da disciplina Débora apresentou o resultado de sua pesquisa e foi convidada para dar continuidade deste estudo ao longo do próximo semestre no âmbito das atividades do Navisual. Nesta oportunidade, toda equipe compartilha do processo de montagem da exposição e, como prática de restituição, participam da etapa de devolução do trabalho de pesquisa pelo suporte da exposição, tornando tangível as memórias desses moradores.

Iluminuras, Porto Alegre, v. 15, n. 35, p. 451-461, jan./jul. 2014 


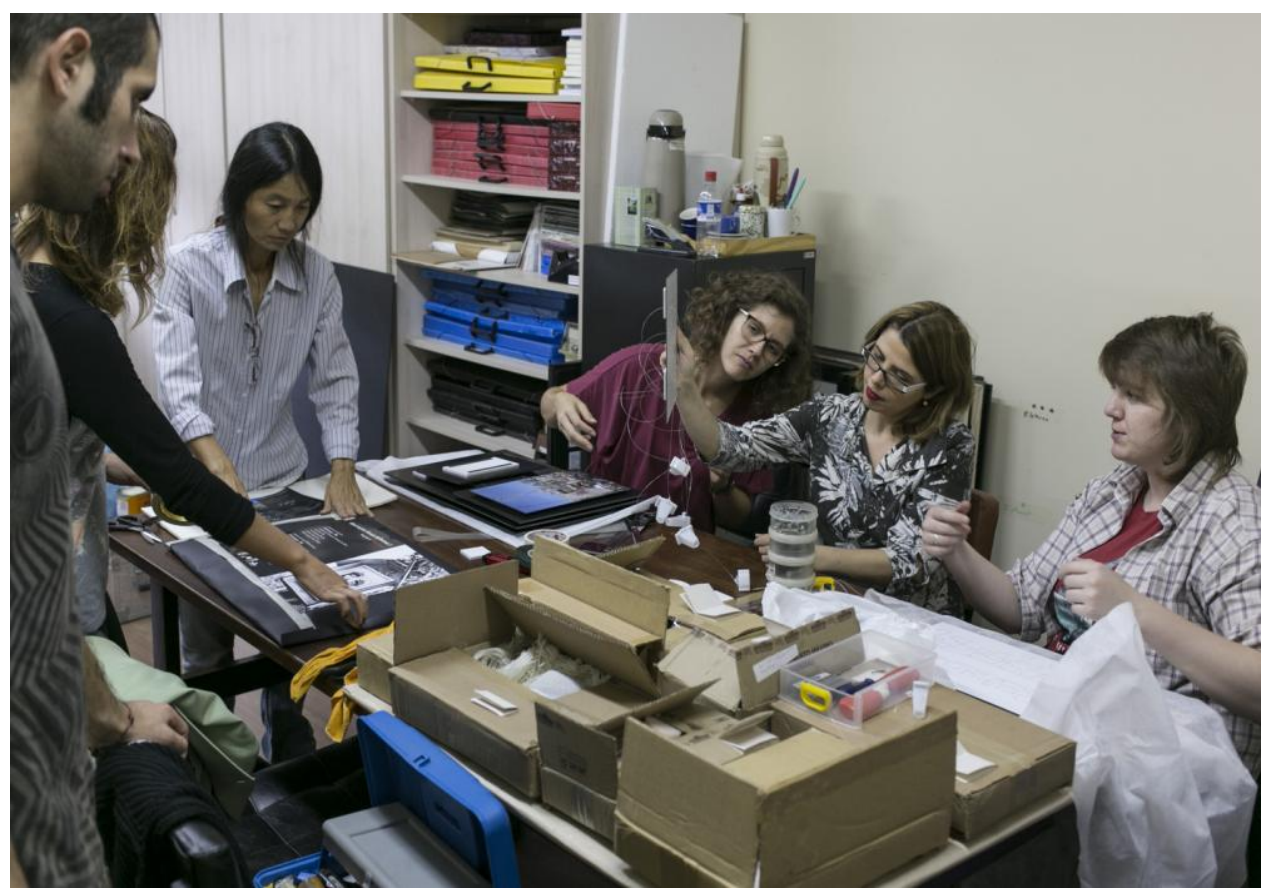

Foto 4 - Montagem da exposição - Júnior, Juliana, Rumi, Roberta, Aline e Débora (da esquerda para direita). Foto: Fabrício Barreto

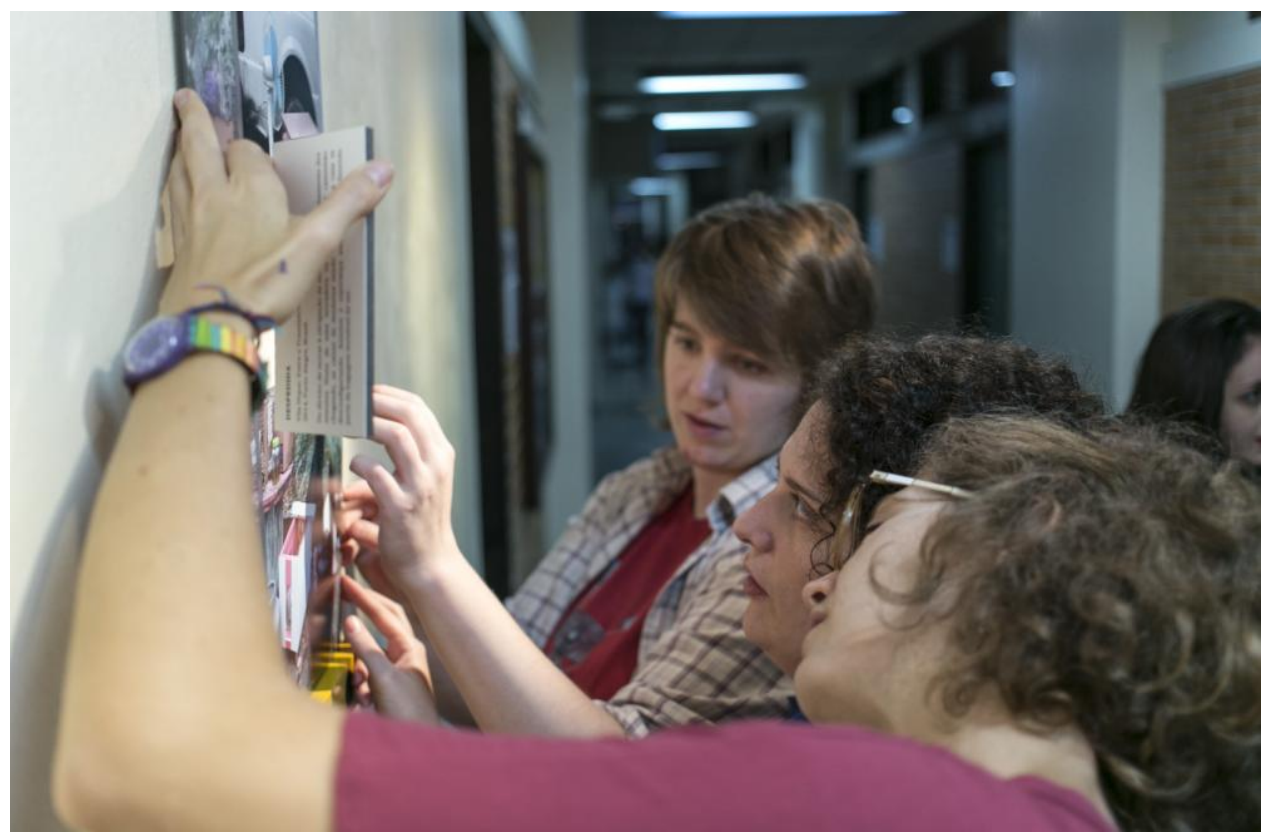

Foto 5 - Roberta, Fabiela e Débora ajustam painéis na galeria. Foto: Juliana Goulart

A forma como a disposição foi pensada e transposta para as paredes da galeria, reflete o trabalho que a equipe do núcleo teve em estruturar dispositivos de narrar o processo de modificações e o dia a dia de seus habitantes nesta experiência de remoção

Iluminuras, Porto Alegre, v. 15, n. 35, p. 451-461, jan./jul. 2014 
compulsória. Em todo o momento as fotos e instalações dão uma dimensão do drama vivido, mas ao mesmo tempo humanizam a forma de ser contada essa história através de um processo de reconhecimento.

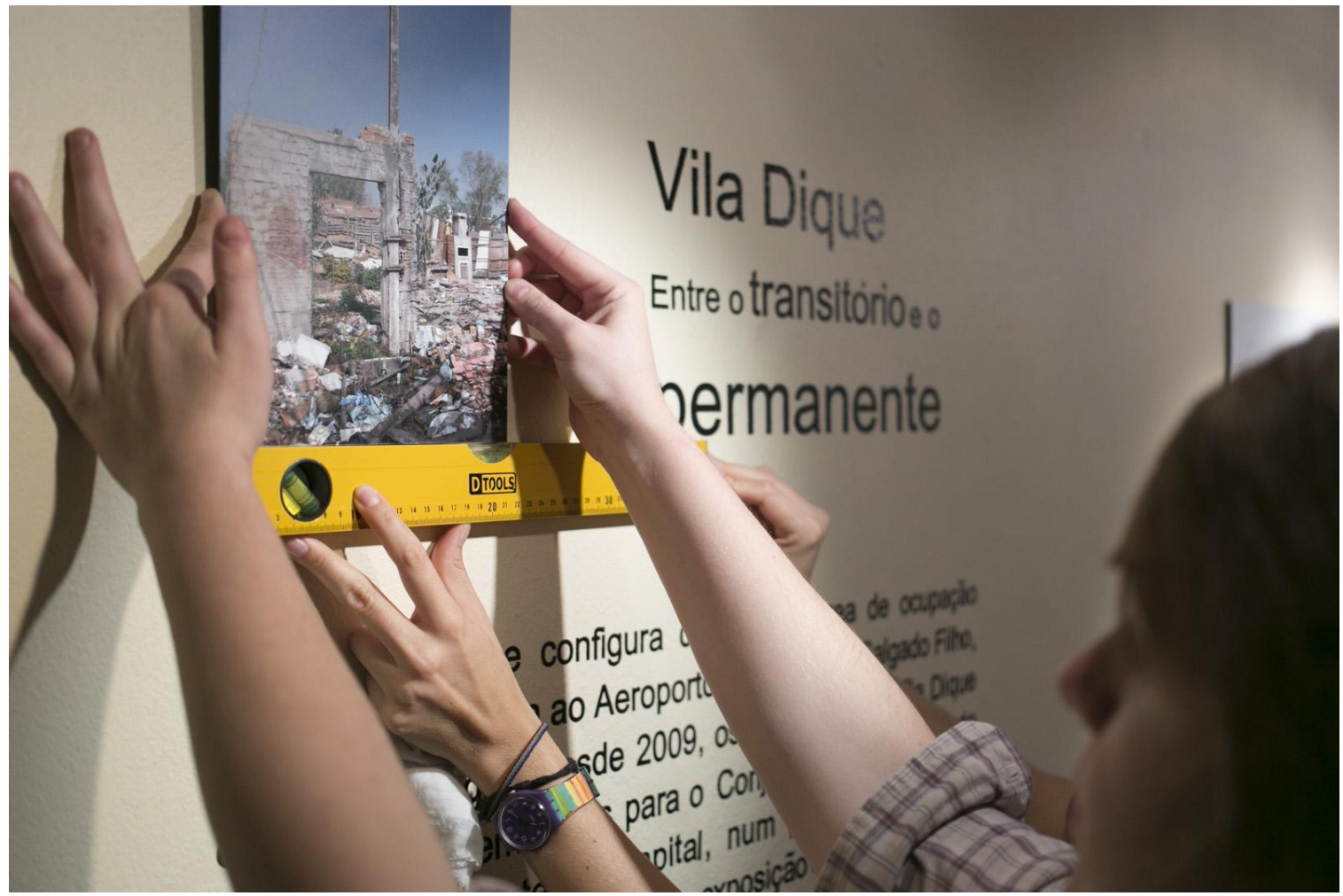

Foto 6 - Débora e Roberta ajustam foto e texto de abertura da exposição. Foto: Fabrício Barreto 


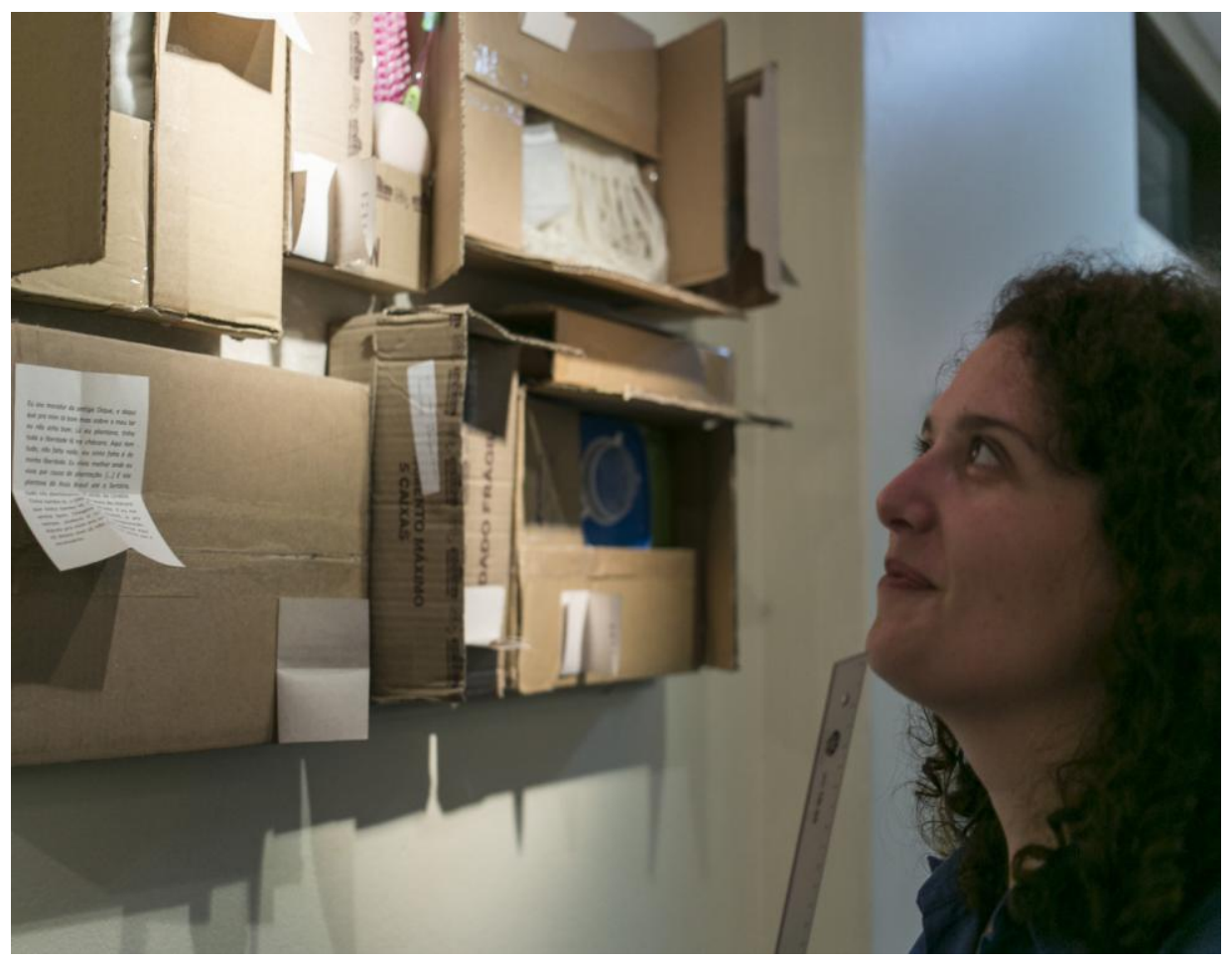

Foto 7 - Fabiela confere a instalação com os pertences de moradores. Foto: Fabrício Barreto

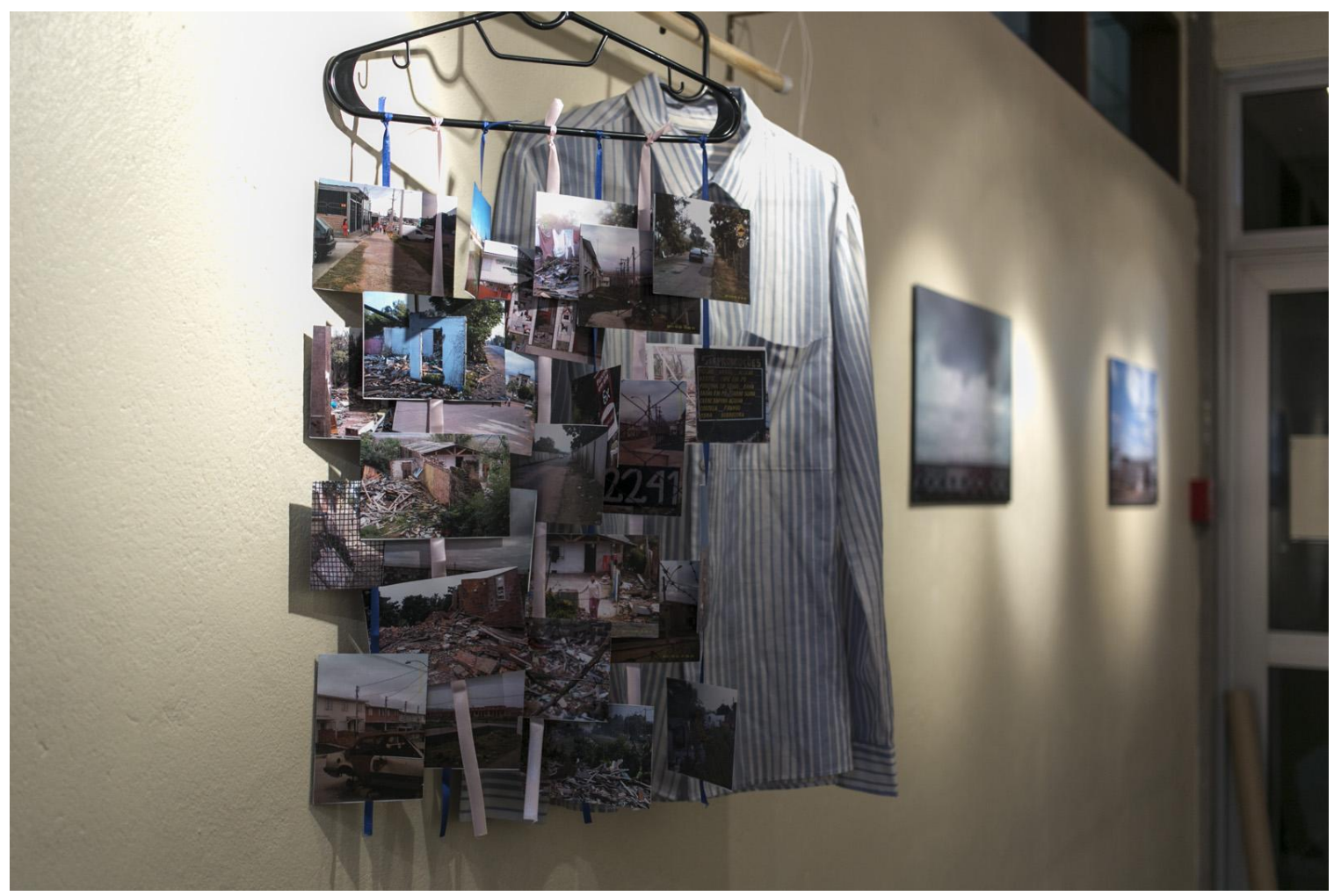

Foto 8 - instalação projetando pertences e fotos dos moradores. Foto: Juliana Goulart

Iluminuras, Porto Alegre, v. 15, n. 35, p. 451-461, jan./jul. 2014 
Ao meu ver, as instalações, que participam da exposição, outra forma de apresentar a Vila Dique, através das caixas que insinuam pertences de moradores ou mesmo o mapa comparativo das estruturas das moradias, são o grande ponto de aproximação com as modificações que acontecem na Vila Dique, especialmente com as histórias dos moradores.

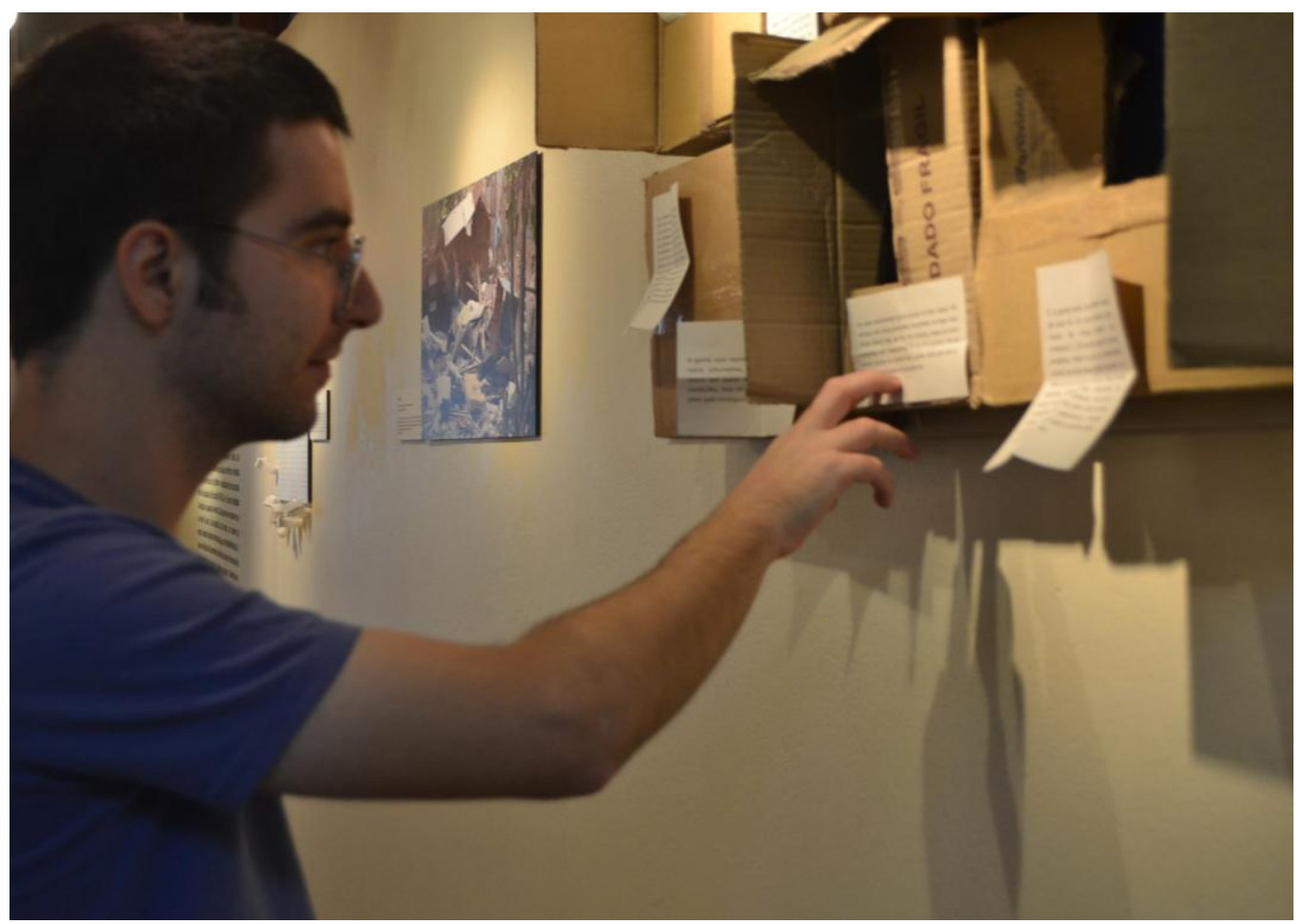

Foto 9 - Abertura da exposição, na Galeria Olho Nu, dia 6 de maio de 2014. Foto: Juliana Goulart

Gosto particularmente da expressão usada pela autora "a pessoa encaixota sua vida", pois essa analogia deixa claro o momento transitório em que se encontram e a maneira apressada com que tiveram que sair da Vila, - colocar seus pertences, histórias e memórias em caixas -, para se reconstruir em um local completamente diferente. Enquanto isso, outros moradores, que ainda esperam ser acomodados vivem meio a este cenário de destruição. 


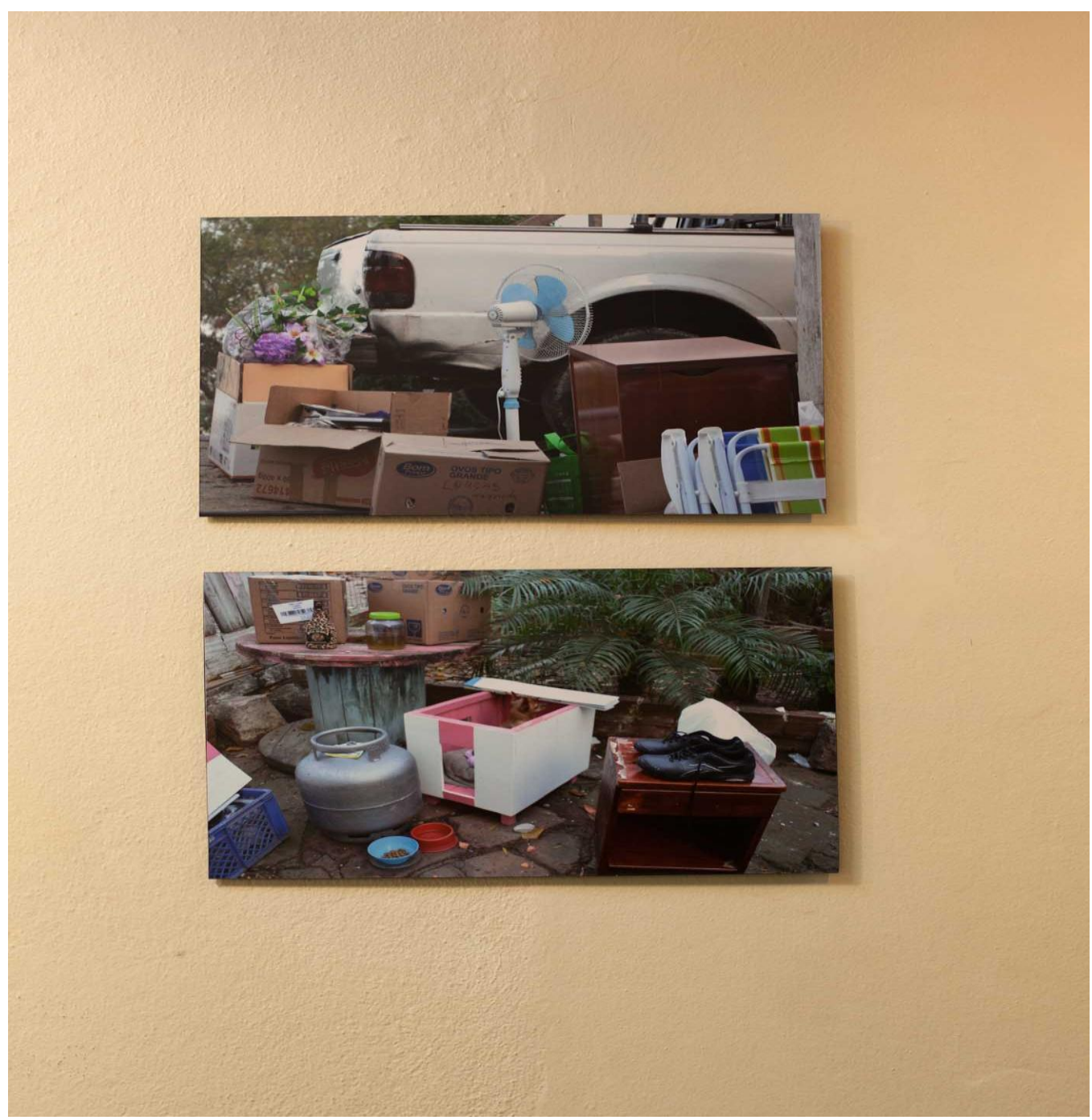

Foto 10 - Foto dos pertences dos moradores encaixotados para a mudança.

O Conjunto Habitacional Porto Novo, no bairro Rubem Berta, além de modelar novos hábitos sociais, restringe as estruturas físicas. Os moradores da Vila foram transportados sem aviso prévio, e hoje convivem com novos vizinhos e outros estilos de vida. Aqui vale a reflexão para a delimitação da liberdade, a imposição das grades em busca de privacidade que impõe novas modalidades de relacionamento social. 

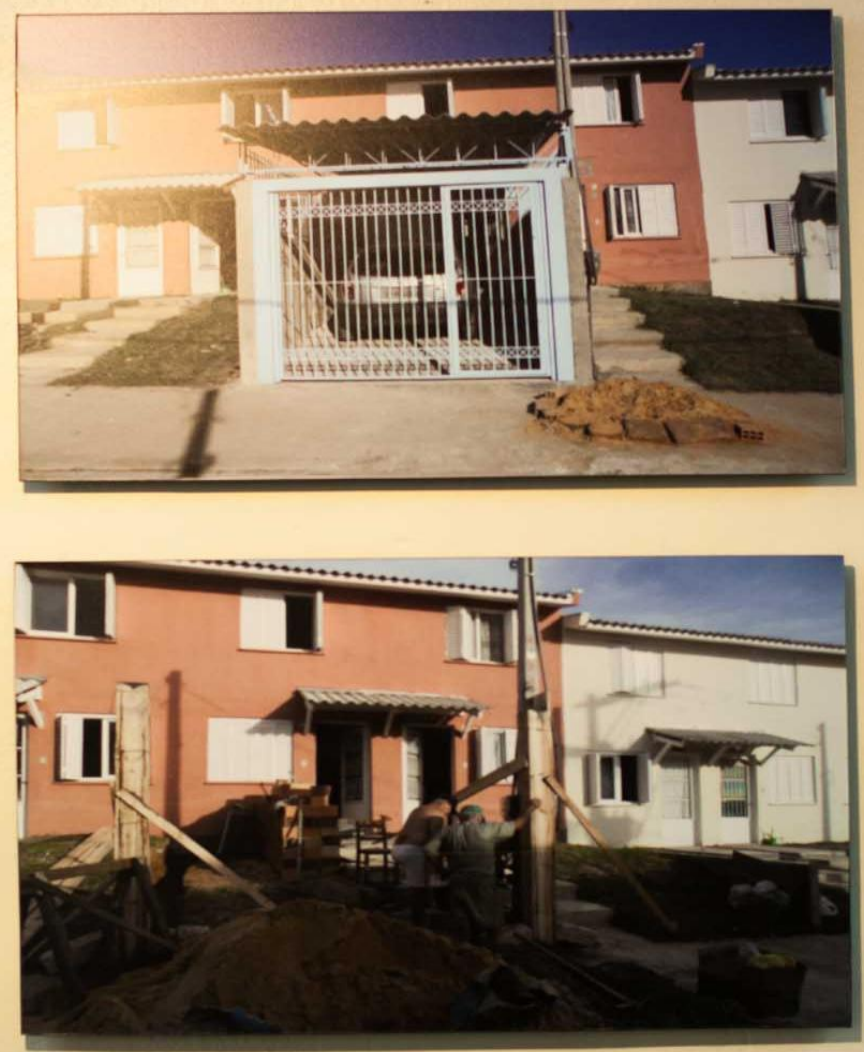

Foto 11 - Foto do Conjunto Habitacional Porto Novo.

Para mim, a grande reflexão é a forma como o espaço de cada morador é desfeito, levando junto suas práticas, seus costumes e sua auto expressão. E quando abriram suas caixas, tinham que colocar dentro desse novo quadrado, suas personalidades mais uma vez.

Iluminuras, Porto Alegre, v. 15, n. 35, p. 451-461, jan./jul. 2014 
A pesquisa-fotográfica interpreta, com o suporte imagético, as desconfigurações e reconfigurações dos habitantes em situação de mobilidade urbana, em especial desta população em uma vila irregular no desejo de se acomodarem (ou não) aos novos projetos de vida na cidade. 